\title{
Expression profile of the tumor suppressor genes DLC-1 and DLC-2 in solid tumors
}

\author{
VERONIKA ULLMANNOVA and NICHOLAS C. POPESCU
}

\author{
Laboratory of Experimental Carcinogenesis, Center for Cancer Research, \\ National Cancer Institute, Bethesda, MD 20892, USA
}

Received April 21, 2006; Accepted May 22, 2006

\begin{abstract}
Several years after the isolation of deleted in liver cancer 1 (DLC-1), a gene that encodes a Rho GTPase activating protein, the closely related DLC-2 gene was identified. DLC-1 and DLC-2 are $\sim 50 \%$ identical and share the same SAM-RhoGAP-START domain organization. Since DLC-1 and -2 are located at chromosome regions that are commonly deleted in cancer cells and have been found to function as tumor suppressor genes, we sought to compare their expression profiles in several common types of cancer and to determine whether $d l c 1$ and $d l c 2$ proteins cooperate in tumor development. Using cancer-profiling arrays, we detected for the first time down-regulation of DLC-1 expression in renal, uterine and rectal cancers and down-regulation of DLC-2 expression in lung, ovarian, renal, breast, uterine, gastric, colon and rectal tumors. Since DLC-1 also functions as a metastasis suppressor gene in breast cancer, DLC-1 and DLC-2 expression were examined in a series of primary ductal carcinomas derived from patients with regional lymph node metastases. Using quantitative RT-PCR we detected a significantly lower expression of DLC-1 and DLC-2 in high percentage of tumors, suggesting that deficiency of either DLC gene facilitates dissemination of breast carcinoma cells to secondary sites. We examined DLC-2 expression in DLC-1negative cell lines derived from human breast, non-small cell lung, and hepatocellular carcinomas, that could be rendered less or non-tumorigenic by ectopic expression of DLC- 1 . DLC-2 transcripts were detected in all cell lines, indicating that none of the cells were deficient in both members of the DLC family. This comparative expression analysis of DLC-1 and -2 identifies down-regulation of the two emerging bona fide tumor suppressor genes in additional types of solid tumors. The large
\end{abstract}

Correspondence to: Dr Nicholas C. Popescu, Laboratory of Experimental Carcinogenesis, National Cancer Institute, Building 37, Room 4128B, 37 Convent Drive, MSC 4262, Bethesda, MD 208924262, USA

E-mail: popescun@mail.nih.gov

Key words: DLC-1, DLC-2, tumor suppressor gene, solid tumor, transcriptional down-regulation, silencing, breast cancer metastasis spectrum of cancers with dysregulated DLC genes underlines the involvement of this family of genes in cancer development.

\section{Introduction}

DLC-1 (deleted in liver cancer 1), a gene that encodes a Rho GTPase-activating protein was cloned as a genomic DNA segment under-represented in a human primary hepatocellular carcinoma (HCC) (1). DLC-1 is located on chromosome 8p21-22, a region of recurrent loss of DNA-copy-number and loss of heterozygosity $(\mathrm{LOH})$ in a variety of human cancers (1). DLC-1 is frequently inactivated or down-regulated in a variety of solid tumors and hematological malignancies and functions as a tumor suppressor gene in breast, lung, ovarian and liver cancers and as a metastasis suppressor gene in breast cancer (2-9). The regulation of Rho GTPase proteins is critical to the neoplastic process and metastasis (10-14). An altered balance between active GTP-bound and inactive GDP-state determines the activity of Rho proteins. DLC-1-mediated negative regulatory effect of cell growth and tumorigenicity is primarily due to RhoGAP ability to inactivate Rho proteins. DLC-1 is a GTP-ase activating protein specific for RhoA and $\mathrm{Cdc} 42$, that are dramatically overexpressed in various cancers $(8,15)$. Frequent structural and functional alterations of the DLC-1 gene and its anti-oncogenic activity suggest potential clinical applications in prevention and early detection of cancer. A high-throughput single nucleotide polymorphism genotyping and gene expression profiling identified DLC-1 as a candidate breast cancer susceptibility gene and the high incidence of DLC-1 methylation in prostate carcinomas may serve as a useful biomarker and in combination with other methylated genes for early detection of prostate cancer (16-18). Cells derived from different types of cancer such as breast, lung, liver or ovarian cancers are highly sensitive to reactivation of DLC-1 function. Thus, the potential for an effective therapy based on DLC-1 transfer to tumor cells appears high.

Two additional members of the DLC family have recently been identified: DLC-2 (STARD13) and DLC-3 (KIAA0189, also known as STARD8) that are $50 \%$ identical to DLC-1 and share the same SAM-RhoGAP-START domain organization (19-22). DLC-2 is located on chromosome 13q12 and is emerging as a tumor suppressor gene due to its inhibitory effect on Ras-induced transformation of rodent cells and suppression of the growth of human breast and liver tumor cells $(20,21,23)$. Like DLC-1, DLC-2 GTP-ase activating 
protein is specific for RhoA and Cdc42 (23). Given the homology and the suppressive activity on proliferation of tumor cells of DLC-1 and DLC-2, the present study was, therefore undertaken to compare the expression of both genes in several types of cancer.

\section{Materials and methods}

Cell culture and primary samples. The cell lines from our laboratory repository or purchased from the American Type Culture Collection (Manassas, VA) were cultured in DMEM/ F12 media with $10 \%$ fetal bovine serum and antibiotics (Biosource, CA) (1). RNA from primary breast tumors and their normal counterparts were obtained from Oncomatrix (San Marcos, CA) while normal liver tissue was from our laboratory repository.

DLC-1 and -2 expression profiling. A cancer profiling array I, containing normalized cDNA from 241 tumors, metastases and corresponding normal tissues from individual patients, was purchased from BD Biosciences (Palo Alto, CA). The DLC-1 probe was amplified from the HLE liver cancer cell line using primers: forward 5' CACAGGACAACCGTTG CCTCGA 3' and reverse 5' CTCTTCAGGGTGTTGAGAT GGA 3'. DLC-2 probe was amplified from HLE liver cancer cell line using primers forward: 5' AGCCCCTGCCTCA AAGTATT 3' and reverse: 5' ATGGGCGTCATCTGATT CTC 3' (14). PCR of both genes was carried out as follows: $\left(95^{\circ} \mathrm{C}, 1 \mathrm{~min} ; 55^{\circ} \mathrm{C}, 1 \mathrm{~min} ; 72^{\circ} \mathrm{C}, 1 \mathrm{~min}\right) 35$ cycles, $72^{\circ} \mathrm{C}$, 7 min. Purified PCR products were labeled with $\alpha-{ }^{32} \mathrm{P}-\mathrm{dATP}$ using a Prime- $\mathrm{It}^{\mathrm{TM}}$ II random primer labeling kit (Stratagene, CA). Labeled probe was purified by column chromatography and $15-20 \times 10^{6} \mathrm{cpm}$ of the probe was hybridized overnight with the cancer profiling array I according to the manufacturer's protocol. Autoradiographs were scanned and analyzed by Gene Snap ${ }^{\mathrm{TM}}$ densitometry software. A ubiquitin cDNA probe was prepared using the same protocol from the manufacturer's ubiquitin cDNA and it was used as a hybridization control and for data normalization. DLC- 1 and -2 expressions were first normalized to the expression of ubiquitin control. The difference in the gene expression between normal and tumor tissue was revealed for each sample as a ratio of normal/tumor values of normalized expression. Significant difference was considered when the ratio of normal/tumor was $>1.25$ and $<0.75$.

Real-time RT-PCR of DLC-1 and DLC-2. RNA (5 $\mu \mathrm{g})$ from 24 breast tumors originating from patients with regional lymph node metastases and matching normal breast tissue was transcribed into cDNA using a cDNA archive kit (Applied Biosystems, NJ). Real-time RT-PCR of DLC-1 used the manufacturer's Taq Man ${ }^{\circledast}$ probe DLC1-1_P and primers DLC1-1499R, DLC1-1416F (Applied Biosystems). Real-time RT-PCR of DLC-2 (STARD13) was performed using SYBR Green I PCR master mix (Superarray, MD) and commercial primers designed for specific real-time RT-PCR of STARD13 (Superarray). The specific peak of DLC-2 was checked by melting-curve analysis. Real-time RT-PCR of GAPDH was carried out according to the manufacturer's protocol using commercial Taq Man probe and primers (TaqMan GAPDH
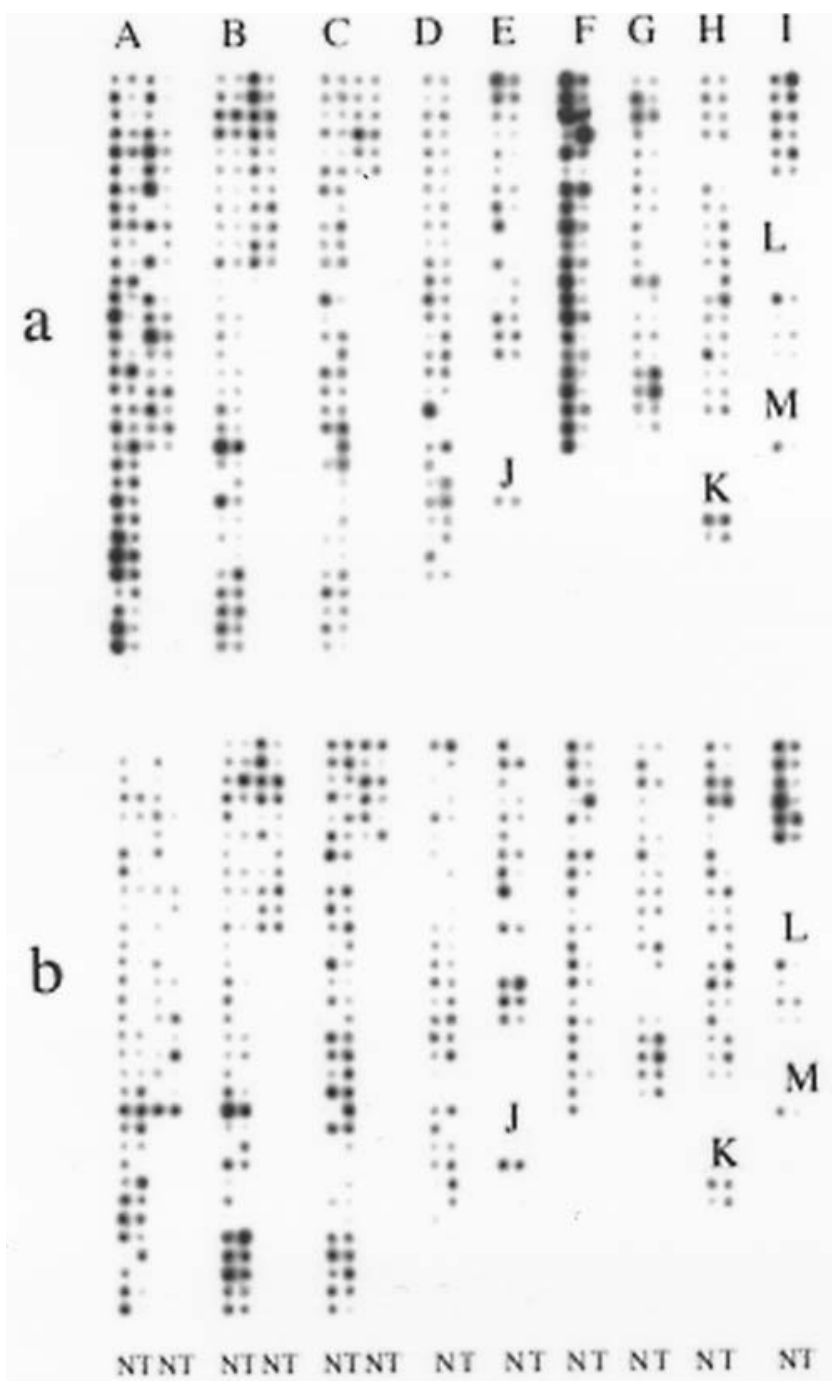

Figure 1. DLC-1 (a) and DLC-2 (b) expression in tumor and normal tissues detected by hybridization of DLC- 1 and DLC- 2 probes with the cancer profiling array $\mathrm{I}$, containing normalized cDNA from tumors and corresponding normal tissues from individual patients. A, breast; B, uterus; C, colon; D, stomach; E, ovary; F, lung; G, kidney; H, rectum; I, thyroid; $\mathrm{J}$, cervix; K, small intestine; L, prostate; M, pancreas; N, normal tissue; $\mathrm{T}$, tumor counterparts.

Control Reagents, Applied Biosystems). The same reaction efficiency of all PCR systems was revealed from standard curves. All real-time PCR reactions were carried out using an ABI PRISM 7900. DLC-1 and -2 expression was first normalized to GAPDH control gene. The difference in the gene expression between normal and tumor tissue was revealed by the $2^{-\Delta \Delta c t}$ method for each sample. Significant difference was considered when $2^{-\Delta \mathrm{Act}}$ was $\geq 2$ and $\leq 0.5$.

$R T-P C R$ of DLC-2. Total RNA from all cancer cell lines was isolated by RNeasy ${ }^{\mathrm{TM}}$ mini kit (Qiagen, CA) and $5 \mu \mathrm{g}$ of RNA was transcribed using the cDNA archive kit (Applied Biosystems). RT-PCR of DLC-2 used primers and conditions as described above with the exception of 30 cycles instead of 35. GAPDH was used as an internal control gene. PCR of GAPDH was carried out as follows: $\left(95^{\circ} \mathrm{C}, 1 \mathrm{~min} ; 61^{\circ} \mathrm{C}, 1 \mathrm{~min}\right.$; $\left.72^{\circ} \mathrm{C}, 1 \mathrm{~min}\right) 33$ cycles, $72^{\circ} \mathrm{C}, 7$ min using primers: reverse 5' AGGGGAGATTCAGTGTGGTG 3' and forward 5' CGA CCACTTTGTCAAGCTCA 3'. 


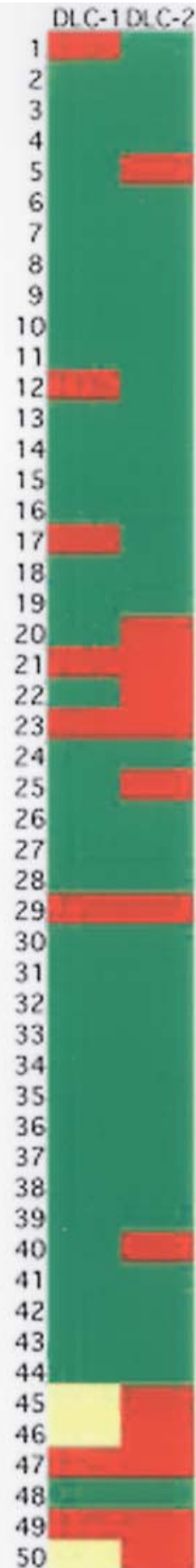

\begin{tabular}{l|c|c|c|}
\multicolumn{1}{c}{ DLC-1DLC-2 } & DLC-1 DLC-2 & DLC-1DLC-2 & DLC-1DLC-2 \\
51 & 97 & 134 & 168 \\
52 & 98 & 135 & 169 \\
53 & 99 & 136 & 170 \\
54 & 100 & 137 & 171 \\
55 & 101 & 138 & 172 \\
56 & 102 & 139 & 173 \\
57 & 103 & 140 & 174 \\
58 & 104 & 141 & 175 \\
59 & 105 & 142 & 176 \\
60 & 106 & 143 & 177 \\
61 & 107 & 144 & 178 \\
62 & 108 & 145 & 179 \\
63 & 109 & 146 & 180 \\
64 & 110 & 147 & 181 \\
65 & 11 & 148 &
\end{tabular}
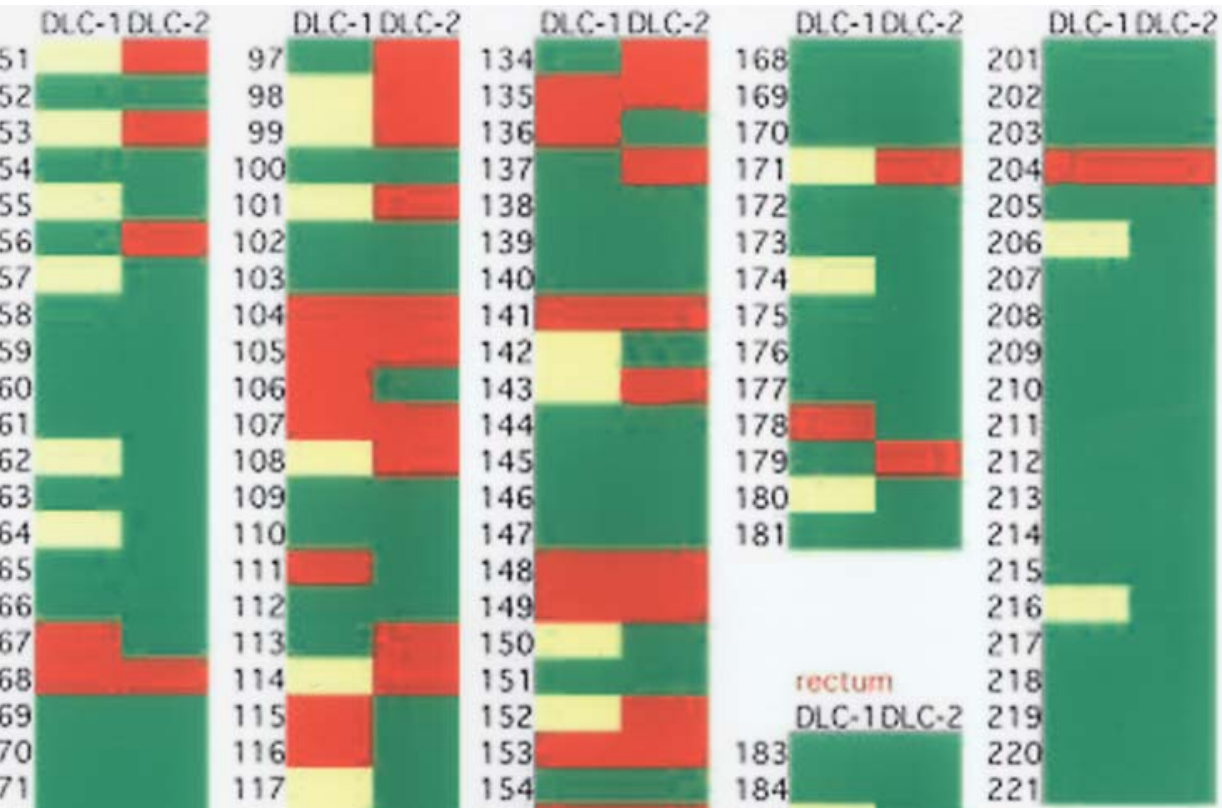

$\begin{array}{ll}66 & 112 \\ 67 & 113\end{array}$

68
69 $\quad \begin{aligned} & 114 \\ & 115\end{aligned}$

$70 \quad 116$

71

72

73

131


222

223

224

225

226

227

228

229

230

231

232

233

234

235

236

237

238

239

240

241

Figure 2. Summary of DLC-1 and DLC-2 expression in different tissues obtained after data normalization to ubiquitin control and analysis by Gene Snap ${ }^{\text {TM }}$ densitometry software. Samples are divided in groups according to tissue of origin. Up-regulation (red), down-regulation (green) and no change (yellow) of DLC-1 and DLC-2 expression is shown for each sample. Numbers refer to appropriate sample identification on the cancer profiling array I. The difference between normal and tumor tissue was revealed for each sample as a ratio of normal/tumor values of ubiquitin-normalized expressions.

\section{Results}

Expression of DLC-1 and DLC-2 in tumor and normal tissues. To assess the involvement of DLC-1 and DLC-2 in various types of cancer we compared their expression by using a cancer profiling array I containing 241 tumor and normal tissue samples derived from patients with breast, uterine, colon, gastric, ovarian, lung, renal and rectal cancer. Array expression analysis showed that both genes are recurrently down-regulated in several forms of solid tumors. We detected a reduced expression of DLC-1 and DLC-2 in a significant number of tumor samples derived from lung, ovarian, renal, breast, uterine, gastric, colon and rectal cancers as compared to the matched normal tissue (Fig. 1, Table I). The percentages of tumor samples exhibiting down-regulation of both genes ranged from $<50 \%$ in colon and gastric tumors to $60-80 \%$ in uterine, breast, renal and ovarian tumors to as high as $90 \%$ in lung tumors (Table I). In rectal tumors DLC-2 was more 
Table I. DLC-1 and DLC-2 expression in various types of solid tumors.

\begin{tabular}{|c|c|c|c|c|c|c|}
\hline \multirow{2}{*}{$\begin{array}{l}\text { Tissue (total number } \\
\text { of samples) }\end{array}$} & \multicolumn{2}{|c|}{ DLC-1 $(\%)^{\mathrm{a}}$} & \multicolumn{2}{|c|}{ DLC-2 $(\%)^{\mathrm{a}}$} & \multicolumn{2}{|c|}{ Loss of DNA copy-number $(\%)^{\mathrm{b}}$} \\
\hline & Up & Down & Up & Down & $8 \mathrm{p}$ & $13 q$ \\
\hline Lung (21) & 5 & 90 & 9 & 91 & $40-69$ & $70-100$ \\
\hline Ovary (14) & 7 & 79 & 14 & 86 & $40-69$ & $40-69$ \\
\hline Kidney (20) & 5 & 75 & 20 & 65 & $<40$ & $<40$ \\
\hline Breast (50) & 14 & 76 & 20 & 72 & $<40$ & $40-69$ \\
\hline Uterus (42) & 12 & 64 & 24 & 64 & - & $40-69$ \\
\hline Colon (35) & 37 & 43 & 37 & 46 & $70-100$ & - \\
\hline Stomach (27) & 41 & 41 & 52 & 37 & - & - \\
\hline Rectum (18) & 39 & 28 & 22 & 61 & - & - \\
\hline
\end{tabular}

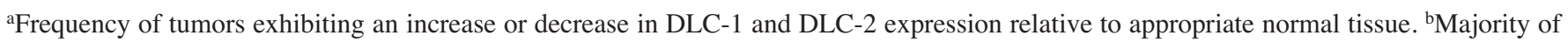
tumors with a reduced expression of DLC-1 and DLC-2 also exhibit with high frequency loss of $8 \mathrm{p}$ and $13 \mathrm{q}$ as depicted by comparative genomic hybridization (reviewed in ref. 28).

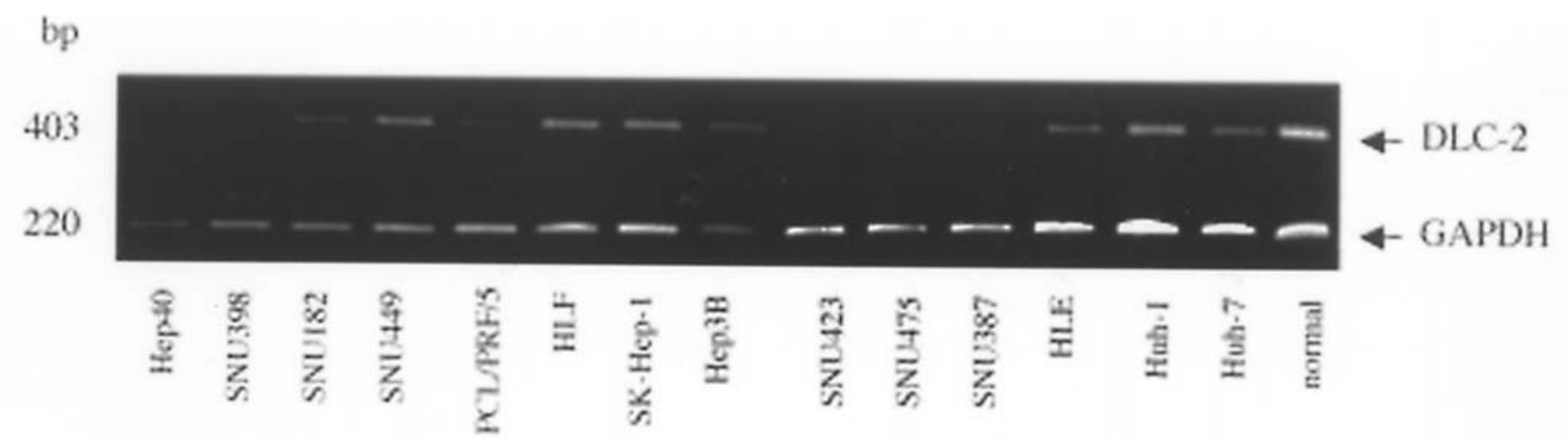

Figure 3. Expression of DLC-2 in human hepatocellular carcinoma cell lines and a normal liver tissue sample. RT-PCR of DLC-2 and GAPDH genes was performed as described in Material and methods. The expression of DLC-1 gene in human hepatocellular carcinoma cell lines for comparison of both genes was reported earlier (18). GAPDH was used as an internal control of amplification.

frequently down-regulated than DLC-1 (Table I). A schematic representation of these data in Fig. 2 and the percentages shown in Table I illustrate that both DLC genes are consistently down-regulated at approximately the same frequency in a variety of solid tumors.

Expression of DLC-2 in liver cancer cell lines. Since samples derived from $\mathrm{HCC}$ were not included in the cancer profiling array I and given the fact that both DLC- 1 and 2 genes are located at regions prone to deletion and $\mathrm{LOH}$ in $\mathrm{HCC}$, we examined the expression of DLC-2 by RT-PCR in 14 HHC cell lines previously characterized for DLC-1 expression (24). While DLC-2 was expressed in normal liver tissue, five HCC cell lines, Hep40, SNU398, SNU-423, SNU-475 and SNU-387, lacked expression of DLC-2 mRNA expression (Fig. 3). A comparison of both DLC genes expression determined in the same cell lines demonstrated that DLC-2 is more frequently down-regulated than DLC-1 in HCC cell lines (24).

Expression of DLC-1 and DLC-2 in metastatic breast tumors. Previous investigations with breast cancer have shown that DLC-1 is frequently down-regulated or silenced in cell lines derived from aggressive metastatic tumors $(4,9)$. Restoration of DLC-1 expression in cell lines derived from metastatic breast adenocarcinomas with low levels of endogenous gene expression caused significant growth inhibition and prevented the development of tumors and reduced the ability of metastatic cells to form pulmonary metastases in athymic mice $(4,9)$. The expression of DLC-1 and DLC-2 was examined by real-time RT-PCR in 12 breast ductal carcinomas from patients with regional lymph node metastases and their corresponding normal breast tissue. A significant level of DLC-1 and DLC-2 down-regulation was detected in $91 \%$ and $73 \%$ of tumors, respectively, that disseminated to 1 or to as many as 8 lymph nodes (Fig. 4).

Expression of DLC-2 in cancer cell lines lacking expression of $D L C$-1. To see whether DLC-2 interferes with the ectopic expression of DLC-1, the expression of DLC-2 was examined in two breast (MDA-MB-361, MDA-MB-468), two HCC (Focus, 7703) and two non-small cell lung carcinoma (H23, H358) cell lines lacking DLC-1 mRNA expression. Restoration of DLC-1 expression in these lines by transfection of DLC-1 cDNA suppressed in vitro cell proliferation and tumorigenicity in vivo (4-6). DLC-2 mRNA was expressed at different levels in all six cell lines (Fig. 5). 


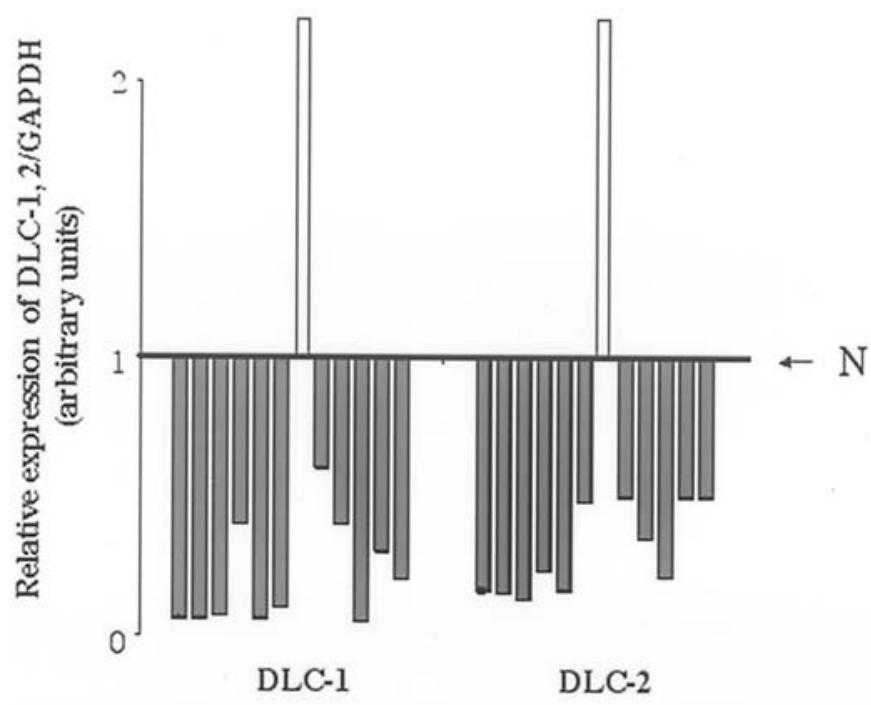

Figure 4. Expression of DLC-1 and DLC-2 in 12 breast ductal carcinomas from patients with regional lymph node metastases and their corresponding normal tissue. Real-time RT-PCR of DLC-1, DLC-2 and control GAPDH genes was described in Material and methods. DLC-1 and DLC- 2 expression was normalized to the expression of control GAPDH and the difference between normal and tumor tissue was revealed by the $2^{-\Delta \Delta c t}$ method. Significant difference was considered when $2^{-\Delta \Delta c t}$ was $\geq 2$ and $\leq 0.5$. Levels of gene expression in normal tissue $(\mathrm{N})$ are set at 1 and indicated by an arrow. Both values, which are over the normal level, belong to the same patient.

\section{Discussion}

This comparative expression analysis provides a wider view of the involvement of DLC-1 and DLC- 2 in human cancer. Cancer profiling array and RT-PCR analyses of tumor cell lines revealed a high frequency of down-regulation of both DLC genes in a variety of solid tumors. Down-regulation or inactivation are hallmarks of tumor suppressor genes and current results underline the notion that both DLC-1 and DLC-2 are emerging as bona fide tumor suppressor genes. Strikingly, both genes are down-regulated in lung, ovarian, renal, breast, uterine, gastric, liver, prostate, colon and rectal tumors as well as in HCC cell lines. Among these cancers, alterations of DLC-1 in renal, uterine and rectal tumors were identified for the first time. Prior to this study alterations of DLC-2 were reported only in liver and breast cancer $(20,21)$. Therefore, both DLC genes may be implicated in considerably more forms of cancer than previously known.

The high incidence of various tumors eliciting downregulation of DLC-1 and DLC-2 can be attributed to both genetic and epigenetic mechanisms. An interesting observation is that the majority of tumors with a reduced expression of DLC-1 and DLC-2 also exhibit a high frequency of loss of $8 p$ and $13 \mathrm{q}$ as depicted by comparative genomic hybridization and recently compiled in a review article (25) (Table I). This is particularly obvious for lung, ovary, kidney and breast cancer. In addition, the loci of both DLC-1 and DLC- 2 are located in regions of $\mathrm{LOH}$ in breast, lung and HCC (26). Tumor suppressor genes that are down-regulated or silenced by promoter hypermethylation are often located in genomic regions of deletion (27). Undoubtedly, promoter hypermethylation or histone deacetylation are major mechanisms

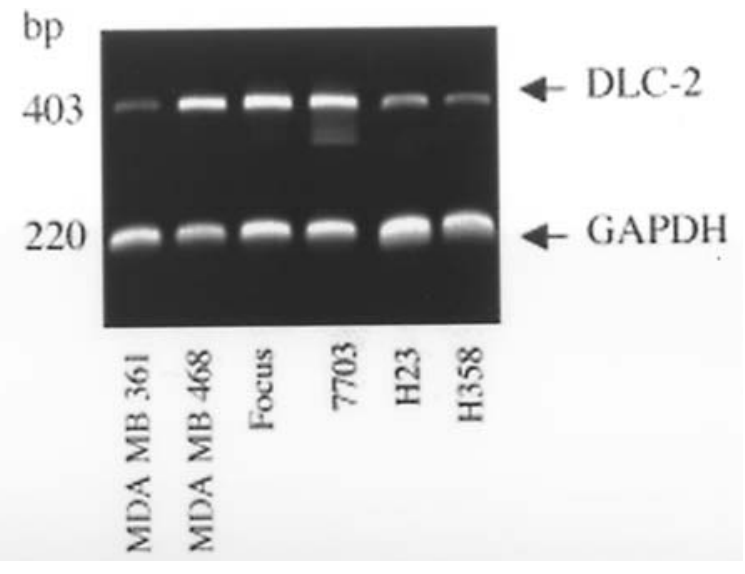

Figure 5. DLC-2 expression in breast carcinoma (MDA-MB-361, MDAMB-468), hepatocellular carcinoma (Focus, 7703) and non-small cell lung carcinoma (H23, H358) cell lines lacking DLC-1. RT-PCR of DLC-2 was performed for comparison of DLC-2 expression with that of DLC-1 gene described earlier (4-6) in the same cell lines. GAPDH was used as an internal control of amplification.

responsible for down-regulation or silencing of DLC-1 in a variety of solid tumors and hematological malignancies (28-34). Most likely, epigenetic modifications account for dysregulation of DLC-2 as well.

DLC-1 expression was previously examined in several different HCC cell lines $(1,2,8,24,29)$. In our series of cell lines, DLC-2 was more frequently down-regulated than DLC-1. However, larger numbers of primary tumors should be examined to validate the extent of DLC- 1 and -2 dysregulation in HCC.

Based on previous investigations demonstrating that DLC-1 functions as a metastasis-suppressor gene in breast cancer (9), we examined DLC-1 and DLC-2 expression in breast tumors from patients with axillary lymph node metastases. Downregulation of both DLC genes in a high number of cases underscores the role of RhoGAP deficiency in the acquisition of invasiveness and tumor cell dispersion at secondary sites. The spread of primary tumor cells to secondary sites is a coordinated and complex process involving interactions between the tumor cells and tissues of the host, changes in actin cytoskeleton organization, alterations of cell adhesion to extracellular matrix proteins, or disruption of cell-to-cell junctions (35-37). Overexpression of either DLC-1 or DLC-2 can disrupt cytoskeleton organization and reduce cell motility $(25,29)$. In addition, rat DLC-1/p122 RhoGAP is localized to focal adhesions, structures that link the actin stress fibers and extracellular matrix receptors (38). DLC-1/p122 RhoGAP was also localized to caveolin-1-enriched plasma membrane domains, suggesting that DLC-1/p122 may play an important role in caveolin distribution through reorganization of the actin cytoskeleton (39).

Our previous investigations with several solid tumor cell lines, consistently demonstrated that ectopic expression of DLC-1 in DLC-1-deficient cell lines, reduced or abolished their tumorigenicity in nude mice. All these lines express DLC-2 at different levels, raising the possibility that DLC proteins cooperate in suppression of cancer cell proliferation. Due to their oncosuppressive function, DLC genes have attracted considerable interest for potential clinical applications in the 
prevention, early detection and therapy of cancer and current observations implicate alterations of both DLC- 1 and -2 in additional forms of cancer.

\section{Acknowledgements}

This work was supported by the Intramural Research Program of the NIH, National Cancer Institute. We thank Drs Aarthi Ashok and John Foley, National Cancer Institute Fellows Editorial Board for editorial assistance with this study.

\section{References}

1. Yuan BZ, Miller MJ, Keck CL, Zimonjic DB, Thorgeirsson SS and Popescu NC: Cloning, characterization, and chromosomal localization of a gene frequently deleted in human liver cancer (DLC-1) homologous to rat RhoGAP. Cancer Res 58: 2196-2199, 1998.

2. Ng IO, Liang ZD, Cao L and Lee TK: DLC-1 is deleted in primary hepatocellular carcinoma and exerts inhibitory effects on the proliferation of hepatoma cell lines with deleted DLC-1. Cancer Res 60: 6581-6584, 2000.

3. Plaumann M, Seitz S, Frege R, Estevez-Schwarz L and Scherneck S: Analysis of DLC-1 expression in human breast cancer. J Cancer Res Clin Oncol 129: 349-354, 2003.

4. Yuan BZ, Zhou X, Durkin ME, Zimonjic DB, Gumundsdottir K, Eyfjord JE, Thorgeirsson SS and Popescu NC: DLC-1 gene inhibits human breast cancer cell growth and in vivo tumorigenicity. Oncogene 22: 445-450, 2003.

5. Zhou X, Thorgeirsson SS and Popescu NC: Restoration of DLC-1 gene expression induces apoptosis and inhibits both cell growth and tumorigenicity in human hepatocellular carcinoma cells. Oncogene 23: 1308-1313, 2004.

6. Yuan BZ, Jefferson AM, Baldwin KT, Thorgeirsson SS, Popescu NC and Reynolds SH: DLC-1 operates as a tumor suppressor gene in human non-small cell lung carcinomas. Oncogene 23: 1405-1411, 2004.

7. Syed V, Mukherjee K, Lyons-Weiler J, Lau KM, Mashima T, Tsuruo T and Ho SM: Identification of ATF-3, caveolin-1, DLC-1, and NM23-H2 as putative antitumorigenic, progesteroneregulated genes for ovarian cancer cells by gene profiling. Oncogene 24: 1774-1787, 2005.

8. Wong CM, Yam JW, Ching YP, Yau TO, Leung TH, Jin DY and Ng IO: Rho GTPase-activating protein deleted in liver cancer suppresses cell proliferation and invasion in hepatocellular carcinoma. Cancer Res 65: 8861-8868, 2005.

9. Goodison S, Yuan J, Sloan D, Kim R, Li C, Popescu NC and Urquidi V: The RhoGAP protein DLC-1 functions as a metastasis suppressor in breast cancer cells. Cancer Res 65: 6042-6053, 2005.

10. Boettner B and Van Aelst L: The role of Rho GTPases in disease development. Gene 286: 155-174, 2002.

11. Jaffe $A B$ and Hall A: Rho GTPases in transformation and metastasis. Adv Cancer Res 84: 57-80, 2002.

12. Moon SY and Zheng Y: Rho GTPase-activating proteins in cell regulation. Trends Cell Biol 13: 13-22, 2003.

13. Gomez del Pulgar T, Benitah SA, Valeron PF, Espina C and Lacal JC: Rho GTPase expression in tumourigenesis: evidence for a significant link. Bioessays 27: 602-613, 2005.

14. Ridley AJ: Rho proteins and cancer. Breast Cancer Res Treat 84: 13-19, 2004.

15. Fritz G, Just I and Kaina B: Rho GTPases are overexpressed in human tumors. Int J Cancer 81: 682-687, 1999.

16. Tang K, Oeth P, Kammerer S, Denissenko MF, Ekblom J, Jurinke C, van den Boom D, Braun A and Cantor CR: Mining disease susceptibility genes through SNP analyses and expression profiling using MALDI-TOF mass spectrometry. J Proteome Res 3: 218-227, 2004.

17. van den Boom D, Beaulieu $\mathrm{M}$ and Oeth $\mathrm{P}$, et al: MALDI-TOF MS: a platform technology for genetic discovery. Int J Mass Spectrom 238: 173-188, 2004.

18. Guan M, Zhou X, Soulitzis N, Spandidos DA and Popescu NC: Aberrant methylation and deacetylation of DLC-1 gene in prostate cancer; potential clinical applications. Clin Cancer Res 12: 1412-1419, 2006.
19. Nagase T, Seki N, Ishikawa K, Tanaka A and Nomura N: Prediction of the coding sequences of unidentified human genes. V. The coding sequences of 40 new genes (KIAA0161KIAA0200) deduced by analysis of cDNA clones from human cell line KG-1. DNA Res 3: 17-24, 1996.

20. Ching YP, Wong CM, Chan SF, Leung TH, Ng DC, Jin DY and $\mathrm{Ng}$ IO: Deleted in liver cancer (DLC) 2 encodes a RhoGAP protein with growth suppressor function and is underexpressed in hepatocellular carcinoma. J Biol Chem 278: 10824-10830, 2003.

21. Nagaraja GM and Kandpal RP: Chromosome 13q12 encoded Rho GTPase activating protein suppresses growth of breast carcinoma cells, and yeast two-hybrid screen shows its interaction with several proteins. Biochem Biophys Res Commun 313: 654-665, 2004.

22. Popescu NC and Durkin ME: Rho GTPase activating protein cDNA on chromosome 13q12 is the deleted in liver cancer (DLC2) gene. Biochem Biophys Res Commun 315: 781, 2004.

23. Leung TH, Ching YP, Yam JW, Wong CM, Yau TO, Jin DY and Ng IO: Deleted in liver cancer 2 (DLC2) suppresses cell transformation by means of inhibition of RhoA activity. Proc Natl Acad Sci USA 102: 15207-15212, 2005.

24. Park SW, Durkin ME, Thorgeirsson SS and Popescu NC: DNA variants of DLC-1, a candidate tumor suppressor gene in human hepatocellular carcinoma. Int J Oncol 23: 133-137, 2003.

25. Struski S, Doco-Fenzy M and Cornillet-Lefebvre P: Compilation of published comparative genomic hybridization studies. Cancer Genet Cytogenet 135: 63-90, 2002.

26. Chinen K, Isomura M, Izawa K, Fujiwara $Y$, Ohata $H$, Iwamasa $T$ and Nakamura $Y$ : Isolation of 45 exon-like fragments from $8 \mathrm{p} 22 \rightarrow \mathrm{p} 21.3$, a region that is commonly deleted in hepatocellular, colorectal, and non-small cell lung carcinomas. Cytogenet Cell Genet 75: 190-196, 1996.

27. Jones PA and Baylin SB: The fundamental role of epigenetic events in cancer. Nat Rev Genet 3: 415-428, 2003.

28. Kim TY, Jong HS, Song SH, Dimtchev A, Jeong SJ, Lee JW, Kim NK, Jung $M$ and Bang YJ: Transcriptional silencing of the DLC-1 tumor suppressor gene by epigenetic mechanism in gastric cancer cells. Oncogene 22: 3943-3951, 2003.

29. Wong CM, Lee JM, Ching YP, Jin DY and Ng IO: Genetic and epigenetic alterations of DLC-1 gene in hepatocellular carcinoma. Cancer Res 63: 7646-7651, 2003.

30. Yuan BZ, Durkin ME and Popescu NC: Promoter hypermethylation of DLC-1, a candidate tumor suppressor gene, in several common human cancers. Cancer Genet Cytogenet 140: 113-117, 2003.

31. Dammann R, Strunnikova M, Schagdarsurengin U, Rastetter M, Papritz M, Hattenhorst UE, Hofmann HS, Silber RE, Burdach S and Hansen G: CpG island methylation and expression of tumour-associated genes in lung carcinoma. Eur J Cancer 41: 1223-1236, 2005.

32. Lodygin D, Epanchintsev A, Menssen A, Diebold J and Hermeking H: Functional epigenomics identifies genes frequently silenced in prostate cancer. Cancer Res 65: 4218-4227, 2005.

33. Pang JC, Chang Q, Chung YF, Teo JG, Poon WS, Zhou LF, Kong $X$ and Ng HK: Epigenetic inactivation of DLC-1 in supratentorial primitive neuroectodermal tumor. Hum Pathol 36: 36-43, 2005

34. Song YF, Xu R, Zhang XH, Chen BB, Chen Q, Chen YM and Xie Y: High frequent promoter hypermethylation of DLC-1 gene in multiple myeloma. J Clin Pathol JCP Published Online First: 17 February 2006. doi:10.1136/jcp.2005.0313772006.

35. Fidler IJ: Host and tumour factors in cancer metastasis. Eur J Clin Invest 20: 481-486, 1990.

36. Lu Z, Ghosh S, Wang Z and Hunter T: Downregulation of caveolin-1 function by EGF leads to the loss of E-cadherin, increased transcriptional activity of beta-catenin, and enhanced tumor cell invasion. Cancer Cell 4: 499-515, 2003.

37. Lozano E, Betson M and Braga VM: Tumor progression: Small GTPases and loss of cell-cell adhesion. Bioessays 25: 452-463, 2003.

38. Yamaga M, Sekimata M, Fujii M, Kawai K, Kamata H, Hirata H, Homma Y and Yagisawa H: A PLCdelta1-binding protein, p122/RhoGAP, is localized in caveolin-enriched membrane domains and regulates caveolin internalization. Genes Cells 9: 25-37, 2004.

39. Kawai K, Yamaga M, Iwamae Y, Kiyota M, Kamata H, Hirata H, Homma $\mathrm{Y}$ and Yagisawa H: A PLCdelta1-binding protein, p122RhoGAP, is localized in focal adhesions. Biochem Soc Trans 32: 1107-1109, 2004. 